\title{
Erratum to: A slow-fast dynamic decomposition links neutral and non-neutral coexistence in interacting multi-strain pathogens
}

\author{
Erida Gjini ${ }^{1} \cdot$ Sten Madec $^{2}$
}

Published online: 7 February 2017

(C) Springer Science+Business Media Dordrecht 2017

Erratum to: Theor Ecol (2016)

DOI 10.1007/s12080-016-0320-1

The original version of this article unfortunately contains mistakes introduced during the publishing process. The corrections are given in the following list:

1) In the previous html version of the article, the images of Figures 2 and 3 were interchanged. The html version was corrected and now figures match appropriately to their captions.

2) Citations to the "Appendices" in the original html version appeared as "??". The html version was corrected and now shows the appropriate citations.

3) Lastly, a spelling mistake was found in the caption of Figure 3. The word "Graptphical" should be "Graphical". The html and pdf versions were corrected.

The original article was corrected.

The online version of the original article can be found at http://dx.doi.org/ 10.1007/s12080-016-0320-1.

Erida Gjini

egjini@igc.gulbenkian.pt

Sten Madec

Sten.Madec@1mpt.univ-tours.fr

1 Instituto Gulbenkian de Ciência, Rua da Quinta Grande 6, 2780-156 Oeiras, Portugal

2 University of Tours, UMR 7350 LMPT, F-37200 Tours, France 